\title{
The Wild Type as Concept and in Experimental Practice: A History of its Role in Classical Genetics and Evolutionary Theory.
}

\begin{abstract}
Wild types in genetics are specialised strains of laboratory experimental organism which principally serve as standards against which variation is measured. As selectively inbred lineages highly isolated from ancestral wild populations, there appears to be little wild or typical about them. I will nonetheless argue that they have historically been successfully used as stand-ins for nature, allowing knowledge produced in the laboratory to be extrapolated to the natural world. In this paper, I will explore the $19^{\text {th }}$ century origins of the wild type concept, the theoretical and experimental innovations which allowed concepts and organisms to move from wild nature to laboratory domestication c. 1900 (resulting in the production of standardised lab strains), and the conflict among early geneticists between interactionist and atomist accounts of wild type, which would eventually lead to the conceptual disintegration of wild types and the triumph of genocentrism and population genetics. I conclude by discussing how the strategy of using wild type strains to represent nature in the lab has nonetheless survived the downfall of the wild type concept and continues to provide, significant limitations acknowledged, an epistemically productive means of investigating heredity and evolutionary variation.
\end{abstract}

Key Words: Wild Type; Model Organism; Domestication; Classical Genetics; Atomism; Interactionism.

\section{What are Wild Types?}

The term 'wild type' is used in genetics to describe individual organisms or alleles deemed 'normal' or typical for their species. But more concretely wild type is what the standard lab strains of experimental organisms are commonly referred to as. These wild type strains operate as controls to measure variation in model organism systems. As the philosopher Rachel Ankeny observes (2007, pp. 49-50), without establishing a 'wild type' "it is not possible to have a 'norm' against which 'abnormal' (or more precisely, that which is variant) can be compared". Selecting a wild type is therefore "the first step in the underlying strategy [of classical genetics]". The importance of this first step was recognised early on. A 1921 'Report of the Committee on Genetic form and Nomenclature' comments how "In most animals and plants it is convenient to settle on a standard type, preferably the wild type, when this is known. The effects of the various genetic factors are in general to be measured by the departure from type which they bring about" (Little, 1921, p. 176). The importance of the wild type's role as a laboratory instrument for measuring variation has therefore been acknowledged both by early $20^{\text {th }}$ century geneticists and contemporary philosophers of science.

Lab wild types are however neither wild nor typical, but instead constitute a specialised class of domesticated organism, removed from wild spaces into controlled and artificially uniform indoor spaces. Isolated from their ancestral populations, they are forced to adapt to a manmade ecosystem of standardised nutriment, temperature and housing. Given these adaptive demands, plus research requirements such as easy availability, a familiar life history and known tolerance of captive conditions, it should not surprise that most model organisms in genetics have been selected from existing stocks of domesticated or commensal species (Ankeny and Leonelli, 2011), making them effectively doubly separated from 'true' wildness. 
Despite these complications being widely known, claims that lab strains are representative of species in nature have been surprisingly enduring. One still widely used genetics textbook defines 'wild type' as "the type observed in the wild, in other words, in nature" (Griffiths et al., 1999, p. 15). A later textbook (Guttman et al., 2011, p. 128) is admittedly more circumspect, asserting that "the term is useful only for certain experimental organisms: for ordinary human characteristics, such as eye color or blood type, no one allele can be considered the wild-type. And wild populations carry several alleles for many genes". The problem of utilising standard varieties to represent the species in the lab is here indicated, namely that they cannot properly represent the full extent of natural variation. This has led to some overt criticism of the very use of the term 'wild type'. Biologist Ken Weiss has for example blogged (2013) that 'wild type' is outdated terminology that only serves to confuse students, suggesting other terms such as 'reference', 'baseline' or 'control' be preferred.

My aim in writing this piece is not advocating terminological reform. Instead, I wish to place the wild type concept within its historical context and understand the reasons for its operational success in both past and present scientific research. I acknowledge that, literally interpreted, 'wild types' don't really exist. I want, however, to establish the reasons why past biologists thought they might exist, and why the concept has proven successful enough to become embedded within the language and strategy of genetics despite its inherent flaws. I will begin by, moreover, emphasising that some of the historical reasons for denigrating the wild type concept are overstated or based on a false picture of the history of biological thought. Much of the contemporary discomfort with the use of the term 'wild type' derives from the influential mid-twentieth century writings of certain evolutionary biologists involved in the 'Modern Synthesis' of Darwinism and genetics, in particular Theodosius Dobzhansky and Ernst Mayr. Dobzhansky - whose research on the genetics of natural populations did much to invalidate the naïve assumptions about variation in the wild held by lab-bound classical geneticists, e.g. his fellow 'Drosophilists' Alfred Sturtevant and Hermann J. Muller (see Kohler, 1994) - I will return to at the end of this paper. Mayr, though, I will deal with now.

\section{Mayr, Wild Types and 'Typological Thinking'}

In many ways the principal ideologue of the Modern Synthesis, Mayr sought to demarcate the new evolutionary biology from its predecessors and competitors whilst also maintaining a clear link to Darwin's original thought. One means by which he did so was by invoking a dichotomy between 'typological' and 'population thinking' (Mayr, 1959). 'Typological thinking' (also conflated by Mayr with the broader 'essentialism'), is the assumption that species are defined by an underlying and static 'type' or 'essence', and was claimed by Mayr to characterise both pre-Darwinian and anti-Darwinian thought (including the wild type concept employed by classical geneticists). 'Population thinking', the belief that species are nothing but interbreeding populations in a state of constant flux, is attributed by Mayr to Darwin, the revolutionary hero of this narrative, but the revolution is presented as incomplete and endangered until its victory is secured by the Modern Synthesis (Witteveen, 2015 \& 2016). Mayr's dichotomy proved rhetorically useful but came under fire from historians of science (example quote: "This polemic usage does violence to the historical record and confuses contemporary debates rather than clarifies them" [Farber, 1978]). Philosophers of science also defended the historical use of typological strategies in the life sciences as based on best contemporary knowledge and practice, and not as grounded in mere dogmatism (e.g. Sober, 1980). Further analysis over the years has helped deflate Mayr's claim that 
'essentialism' characterised pre-Darwinian natural philosophy (Winsor, 2006; Müller-Wille, 2011), as well as pointing to the benefits of typological methods in biological investigations (Di Teresi, 2010).

When pressured, Mayr admitted the typological-populational dichotomy was a "temporary oversimplification" (Witteveen, 2015). Nevertheless, he had few qualms with using this distinction to anachronistically dismiss swathes of historical research as products of typological delusions. This strategy of presenting the progress of biology as stalled by ideologically imposed 'epistemological obstacles', whilst appealing as narrative, acts to obscure the proximate causes of historical disputes, which would otherwise complicate Mayr's story. ${ }^{1}$ For an example salient to the history of the wild type concept, we see Mayr dispute Provine's claim that "The conflict between the Mendelians and biometricians... drove a wedge between Mendel's theory of heredity and Darwin's theory of continuous evolution" by stating that "It was not this conflict that delayed the synthesis but simply the typological thinking of the Mendelians and their inability to understand the population nature of species" (Mayr, 1973, p. 346). This rhetorical dismissal of early Mendelian thought disregards the fact that what was precisely in dispute was the compositional and evolutionary nature of populations and that the neo-Darwinian concepts of population that emerged in the aftermath of the synthesis were not the same as the 'palaeo-Darwinian' concepts of population maintained by the biometricians. What was needed was precisely the reconciliation of the particulate, discontinuous and biochemically stable nature of Mendelian factors with the Darwinian theory of evolutionary change through the selective accumulation of infinitesimally small 'individual differences', i.e. the synthesis' claimed great achievement. This admirable achievement, however, required half a century of painstaking research and theory in order to reconcile the genuine differences between Darwinism and genetics. It was therefore not simply the case that a synthetic Darwinian theory of the genetics of natural populations could have been arrived at earlier in the $20^{\text {th }}$ century if not for the retarding force of 'typological thinking'.

Understanding the above, I suggest that we take the wild type concept as a serious theory of the composition of natural populations that in its own time was reasonably defensible based on the then available evidence. The attempt to align laboratory standard organisms with some kind of natural standard (see the aforementioned comments of the 1921 Committee on Genetic form and Nomenclature) was motivated by a genuine belief in the real existence of typical or 'normal' forms in nature, and many researchers in early genetics believed that inbred domesticated strains were a means of studying these normal forms of the species under tractable circumstances. Despite well-known divergences between nature and lab, classical geneticists generally believed themselves justified in extrapolating to nature knowledge produced in the lab. This belief can only be understood by placing early genetics in the context of late $19^{\text {th }}$ and early $20^{\text {th }}$ century evolutionary theory. From this we discern that 'wild type' had a prior life before entering the laboratory, being part of a longer history of domestic

\footnotetext{
See Sloan's comments in his review of The Growth of Biological Thought: "Mayr's history is, consequently, normative rather than descriptive; it proceeds by a selection of problems and individuals either relevant to the solution of these problems or to their confusion and lack of clarity"; "[In spite of committing to avoid doing so] In practice, however, he often does use history judgmentally"; "[T]he sharply drawn party labels [of essentialism and antiessentialism] tend in the end not to be helpful. They lead Mayr to miss some insights, and to some extent they perpetuate certain confusions that might have been avoided if he had been willing to view history in a more flexible framework" (Sloan, 1985, p. 147).
} 
organisms standing in for the wild in scientific theory and experiment (see Shapin 2010, pp. 22-3 for more details on 'standing-for' relations). Interrogating this history helps us understand how lab wild types came to play the role they did in classical genetics and what presumptions about the relationship between domestic and wild, artificial and natural, this research strategy depended on for epistemic legitimacy. I shall show this by first investigating the early $19^{\text {th }}$ century origins of the wild type concept, then tracing the theoretical changes that allowed it to move from a concept applied to organisms in wild nature to one which could be applied to domesticated laboratory lineages used for genetic breeding experiments. I will then discuss the tensions that arose within the wild type concept as a result of differing theories of heredity, cytology and evolution and differing research strategies and outcomes, with holist and atomistic conceptions competing. The most successful research programme to emerge from this conflict, chromosomal linkage mapping as pioneered by the Morgan group at Columbia University, would be responsible for the greater standardisation and instrumentalisation of 'wild type' lab lineages but would also contribute to the partial disintegration of the wild type concept due to its genocentrism. I will conclude by discussing how the token-based use of wild type lineages to represent variation in nature was brought into question by new understandings of genetic diversity in the wild, leading to my final assessment of the relative merits and demerits of wild types as stand-ins for nature in laboratory genetics experiments.

\section{A Preliminary to Wild Type}

The original gestation of the wild type concept can be traced to around 1800 (with the term first appearing in English in the 1820s) and was grounded in three main assumptions: (a) domestic organisms descend from wild ancestors; (b) domestication is an artificial state requiring human maintenance; and (c) the wild state is a species' natural state, towards which it is inherently inclined and will revert towards when removed from domestication (this representation of variation constitutes a kind of 'natural state model') (Sober, 1980). These grounding assumptions would be reflected in the three major meanings of 'wild type' - a genealogical usage referencing domestic varieties' wild ancestry; a comparative usage tracking the effects of domestication through contrasting domestic varieties with their wild relatives; and a normative usage associated with reversion. An early example of the genealogical usage of 'wild type' is by Augustin de Candolle (1823, p. 186-7), who states that "the "Wild or oleiferous Turnip... appears to be the wild type of the species", pointing to the fact that it was "mentioned, and tolerably described, by ancient authors under the name of Wild Turnip" as evidence that it cannot have been recently derived. For use of wild type in its comparative sense, I point to a commentary (Anon., 1833, p. 148) on the work of French zoologist Isidore Geoffroy St Hilaire. Dividing domestic species into two groups - "those whose races have all the same height, or nearly so, and those which consist of very large and very small races" - it asserts of the first group that "the height of the races or varieties cannot be different from that of the wild type... [or] is always very slight", whereas in the second group "there are some domestic races existing much larger, and others much smaller than the wild type; but the medium height of the domesticated races... hardly differs, or does not differ at all from the wild type". The wild type is here used as a point from which to measure the divergence of domestic varieties. The main referent is not the wild species as past ancestor but rather as present contemporary of domestic varieties. The mode of enquiry is thus principally synchronic not diachronic and phenetic not phylogenetic. Finally, the earliest example I have found of the use of 'wild type' with reference to reversion is in Thomas Bell's 1837 History of British Quadrupeds where, discussing the Shetland bull cattle breed, 
he remarks that "the most interesting circumstance attached to this breed is the obvious tendency which a relaxation of domestic discipline and management produces towards a return to the form of the original wild type" (p. 427).

The establishment of the wild type concept in Anglophone scientific discourse coincided with the period when Charles Darwin was developing his theory of descent with modification. Darwin's theories would qualify and constrain the wild type concept in a number of ways. Most importantly, Darwin insisted on a unitary theory of biological variation as correlated with changes in the conditions of existence. This applied across the domestic-wild divide, i.e. the same kind of processes were assumed responsible for variation in both spheres. This contrasted with the widespread prior assumption that variation in the wild was "rare and evanescent" (as maintained by John Crawfurd, a sceptic of Darwinism, in 1869), natural conditions being believed to be largely stable. It was only when an organism's environment dramatically altered, due to natural catastrophe or forcible displacement into the domestic sphere, that variability was induced. The unnatural character of the stimuli organisms were subjected to under domestication was often cited as a reason to regard such variability as artificial and having no equivalent in nature. Thomas Andrew Knight (1801, p. 3) lists among these influences "a more abundant and regular supply of nourishment than is afforded in a state of nature, with a favourable climate, or protection from the effects of an indifferent one". Other naturalists pointed to the artful nature of the reproductive controls used to maintain domestic varieties (especially the new 'improved' ones), Edward Blyth (1835, pp. 46-7) opining that "if man did not keep up these breeds by regulating the sexual intercourse, they would all naturally soon revert to the original type".

Darwin himself originally held to these orthodox views. He noted that "Most organic beings in a state of nature vary exceedingly little" and attributed the contrasting variability of domestic organisms to "the mutability of the affairs, habits, migrations, and knowledge of man". He did however allow that "organisms in a state of nature must occasionally, in the course of ages, be exposed to analogous influences", and he believed that domestication might thereby serve as evidence for how wild organisms would vary under exceptional but natural environmental pressures (Charles Darwin, 1844, in Francis Darwin [Ed.], 1909, pp. 78 \& 81-4). It was only upon rereading Malthus' Essay on Population that Darwin realised that conditions in nature would be continually destabilised by the competition that resulted from the pressure on resources effected by unchecked reproduction, and that therefore the pressure to remain well-fitted to one's environment would be constant (Ospovat, 1979). Darwin was not first to argue for such a 'concealed war of nature'. The breeder John Sebright spoke of competition in the wild as "by destroying the weak and unhealthy" having "the good effects of the most skilful selection" (Bajema, 1982, pp. 106-7). But Sebright only saw this natural selection as maintaining the standard form of the species. Darwin, however, recognised that the destabilising force of reproductive power would ensure competition even during periods of environmental stasis. Selection favoured individuals best able to compete, so any superior variation would tend to displace its parent type. Even within a stable evolutionary lineage, a wild type would gradually alter over time by incorporating advantageous variations. Nature, like the breeder, was thus making constant adjustments to best fit species to its scheme. Wild types varied much the same way as domestic varieties, the main difference being that nature could fine-tune its modifications by acting "on the whole machinery of life" over aeons, whilst "Man can act only on external and visible characters" over civilisation's brief span (Darwin, 2009, pp. 64 \& 82-3; Cornell, 1984). 
Darwin was forced to defend his unified theory of variation when, in 1867, Fleeming Jenkin claimed that selection could not result in speciation as divergence from type was limited within a "sphere of variation". Jenkin positioned "the average animal at the centre" and asserted that the further an organism deviated, the more inclined it was to revert. He cited as evidence the diminishing returns of selective breeding and its failure to create any true new species. For Jenkin, wild types and domestic varieties were different, the one being natural and varying little, the other artificial and induced to vary by human hand. Darwin responded to Jenkin's normative model of wild type by maintaining that reversion was not the reassertion of a natural inclination but rather caused by the reactivation of traits rendered dormant under domestication. He maintained that "this tendency is largely governed by the nature of the climate, amount of exercise, and other causes of change to which [organisms] have been subjected". Feral pigs, for instance, "reassume their original bristly covering", but did so "in different degrees, dependent on the climate". Those at high altitude were hirsute, those in hot climates thinly haired. Similarly, most individuals regained the wild type coat colour but some pigs in tropical wilds developed red coats instead. Reversion to the shape and proportions of the wild type was also what "might have been expected from the amount of exercise which [feral pigs] are compelled to take in search of food" (Darwin, 1888, pp. 812 ). That reversion to the wild type was in these ways correlated with the organism's new wild environment demonstrated for Darwin that reversion was a mere aspect of the general tendency of organisms to vary under changed conditions.

\section{Weismann \& Galton's Sanctuarisation of Heredity}

Darwin's unified theory of variation presumed that domestication could serve as a useful source of information regarding variation in general, including in nature. However, in assuming a correlation between changes in the conditions of existence and organismic variation, Darwin implied that the character of wild types could not be kept stable for longterm study under domestic conditions. This was further assumed in his theory of generation, pangenesis, which proposed that changes to somatic tissue could be communicated to the germ-line and inherited via the medium of tiny particles called gemmules. The belief in acquired characteristics was popular and ancient but in the later $19^{\text {th }}$ century came into question. Francis Galton had expressed scepticism as early as 1865, observing that the effects of life on inheritance were so insignificant it would not be unwarranted to act as if "our own embryo... [had] sprung immediately from those embryos whence our parents were developed, and these from the embryos of their parents, and so on for ever" (Müller-Wille and Rheinberger, 2012, p. 79). Galton moreover pointed out that ova and testes formed in utero, limiting the possibility for a direct feedback mechanism between changes to living conditions and adaptation of the germ-line of offspring (Galton, 1894).

Whilst Galton did not discount inherited acquired characteristics, he did not believe them to have much evolutionary influence. In the 1880s, August Weismann would come to similar conclusions and formulate them in his influential hypothesis of the sequestration of the germline. Weismann held to a mosaic theory of development whereby embryonic cells differentiated from the homogeneous zygote through the differential parcelling out of hereditary units known as determinants. Adult somatic cells only retained the contingent of units relevant to their specific function, raising a problem for reproduction, since if all cells specialised there would none remaining with the necessary full complement of determinants. Therefore, Weismann reasoned, the hereditary materials in the fertilised egg must be copied 
at the beginning of ontogeny, producing an intact inactivated germ-plasm unutilised in development, which migrates into the reproductive organs. Because there was no feedback mechanism between somatic cells and germ-plasm, any alterations acquired by the former could not be inherited through the latter. Consequently, changes in the conditions of existence could only cause heritable changes through direct modification of the germ-plasm (Amundson, 2005; Stanford, 2006; Winther, 2001).

Weismann's closing off of the germ-line from external influence contributed to what Christoph Bonneuil (2008) has termed the "sanctuarisation" of heredity, whereby hereditary units became "isolated from both the environment and the particular experience of the organism" (pp. 87-8). Sanctuarisation denied the correlation between variation and conditions of existence and thereby legitimised the idea that heredity could be studied under controlled conditions without having to treat the artificial lab environment as a potential interfering factor. Such claims were further supported by what Bonneuil calls 'devitalization' - the move from treating hereditary units as autonomous living entities to instead regarding them as inanimate, stable biochemical macromolecules. Devitalization occurred as part of a wider shift in laboratory biology towards more mechanistic, determinist and physiochemically reductive interpretations of living processes. Prominent figures in this broad tendency included physiologists Julius Sachs and Jacques Loeb and the embryologists Wilhelm His and Wilhelm Roux (Allen, 1978). Devitalization attacked the older Romantic belief in life's spontaneous capacity to self-direct change. Instead, it treated organisms as physiochemical and mechanistic in nature, seeking to understand them by manipulating and decomposing them into fundamental behaviours and particles. As hereditary units became increasingly identified with particular substances - e.g. chromatin and enzymes - a greater effort was made to purify them into their elements, either through biochemical analysis or breeding experiments. The latter method particularly would be employed by early geneticists in their attempt to isolate wild types.

Denying Darwin's correlational theory of variation allowed for the stable isolation of heredity but raised questions as to the origin of variation. Weismann had held that the majority of apparent variance was in fact due to the rearrangement of determinants by sexual reproduction. He attributed the dissimilarities between wild types and domestic varieties not to the production of new determinants but rather to the relaxation of selection, which allowed traits detrimental in the wild to be developed and perpetuated under domestication (Gayon, 1998). The instinct to escape, for instance, was claimed to have undergone "gradual degeneration" due to the "cessation of the action of natural selection" (Weismann, 1891, pp. 23-4). Variation in the wild was similarly due to rearrangement of pre-existing determinants, but their perpetuation was directed by selection towards adaptive ends. Weismann believed selection, like a composer, could produce almost infinite diversity out of a few basic components (Gliboff, 2001). This was not a satisfactory answer for other evolutionists, notably Galton, who was dismissive of the power of selection to produce any permanent novelty. His scepticism was grounded in his discovery of the statistical phenomenon of 'regression to the mean', the tendency of the children of exceptional parents to be closer to the populational average. Galton believed this was due to an ancestral racial heredity overwhelming the influence of divergent parental heredity. Similarities can be drawn between Galton's theory and Jenkin's 'sphere of variation'. Unlike Jenkin, however, Galton did believe evolutionary change was possible but believed it would occur not through the accumulation of ordinary variation but instead through rare and large variations known as sports or 
saltations. Galton proposed that if such variations were inherited exclusively, as opposed to blending, then distinct races could form that were not predisposed to regression (Gould, 2002; Gayon, 1998). The influence of both Weismann and Galton's theories of variation would be visible in the thought of early geneticists.

\section{Mendelism and Biometry: Background to the Dispute}

Sanctuarisation and devitalization contributed to the growing confidence that organisms could be brought into controlled conditions and purified into stable strains characterised by a specific hereditary makeup. The large-scale methodical selective techniques Darwinism had valorised were moreover suffering diminishing returns, leading some plant breeders to resort to alternative methods, such as the mid- $19^{\text {th }}$ century Vilmorin strategy of pedigree line breeding. The commercial power of such 'pure line' methods was demonstrated in the mid1890s when Wilhelm Johannsen showed that the apparent correlation in barley between seed weight and nitrogen content could be overcome by breaking a population down into invariant strains. By identifying and propagating strains with high weight and low nitrogen content, yield could be increased whilst avoiding the detrimental effects of high nitrogen content on the malting process (Müller-Wille and Richmond, 2015). The pure line method soon emerged not only as a commercial competitor to mass selection but also as an experimental challenge to the theory of natural selection. In 1903, Johannsen published the results of biometric experiments on bean size showing that each generation within a pure line exhibited the same range of variation even under intensive selection. Johannsen interpreted this as evidence that all individuals within a pure line shared the same germinal material or 'genotype' (Gayon, 1998).

For those already sceptical of the creative power of natural selection, this implied the primacy of changes in the germinal material in initiating evolutionary change. The Dutch botanist Hugo de Vries had indeed already in 1889's Intracellular Pangenesis suggested that speciation was caused by chance errors in the reproduction of hereditary characters, a hypothesis he would later claim to have found experimental proof for in 1901's Mutation Theory through breeding experiments conducted on the evening primrose Oenothera lamarckiana. Germinal variation was now presented as the main prerequisite for evolution, whereas selection was thought to play no role in actively shaping and directing variation, acting only as a 'sieve' filtering out unfit types. The role of the environment in evolution was thus further downplayed, offering greater encouragement to lab-based breeding strategies, the unnatural experimental conditions of which would previously have invited suspicions of artifice. Concerns regarding the differences between lab and wild ecologies therefore diminished in proportion to the decrease in the evolutionary importance attributed to the conditions of existence.

This was the wider context of the 1900 'rediscovery' of Gregor Mendel's mid-19 ${ }^{\text {th }}$ century breeding experiments. Mendel's findings are likely familiar to the reader, so I will not go into detail, save to say that his demonstration that the 3:1 ratio in monohybrid peas and the 9:3:3:1 in dihybrids was a somatic effect of character dominance was a major breakthrough for the application of line breeding to sexually reproducing organisms. Pure-line methods were dependent on using self-fertile organisms. By showing that hybridised factors did not blend and were instead independently assorted and segregated in inheritance, Mendel demonstrated that varieties of sexually reproducing species could be fixed by selecting individuals with the right hereditary constitution. Mendelism showed, as William Castle (1902, p. 401) observed, 
that "No animal or plant is 'pure' simply because it is descended from a long line of ancestors possessing a desired combination of characters", but on the other hand "any animal or plant is pure if it produces gametes of only one sort, even though its grandparents may among themselves have possessed opposite characters". By disproving the existence of Galton's preparental ancestral heredity, Mendelism denied the need of pedigree for purity. This helped deflate the long-standing problem of reversion, which was instead interpreted in terms of chance combinations of discrete hereditary factors. "Variation and Reversion", William Bateson observed in 1908, were now "definite, physiological event[s]" caused by the "the addition or omission of one or more definite elements" (p. 48). These elements had no memory of ancestral history and it was only coincidental when the loss or gain of an element returned an individual to an ancestral condition. By refuting ancestral heredity, Mendelism ultimately helped complete the "move 'out of history" that had begun with Weismann's sequestration of the germ-line (Bonneuil, 2008).

This move did not come without opposition. Whilst Galton had contributed to the growing scepticism towards natural selection in fin de siècle evolutionary biology through his discovery of regression to the mean and his espousal of saltationalism, his theory of ancestral heredity and his statistical tools for the measurement of variation within populations had also been taken up in the defence of orthodox Darwinism in Britain by the 'biometricians'. Led by Walter Weldon and Karl Pearson, this research school had in the last decade of the $19^{\text {th }}$ century pioneered the attempt to directly study the effects of natural selection by measuring changes over time in the distribution of traits in natural populations (e.g. Weldon's studies of the influence of size in young crabs in determining survival to adulthood) (Gayon, 1998). The biometricians believed their studies to have demonstrated the directive power of gradual selection acting on continuous variation, so were therefore sceptical of the Mendelian claim that the variability of populations could be reduced to the differential combination of independently inherited factors of discontinuous effect, especially when combined with the mutationist assertion that all germinal variation was internally generated.

The Mendelian-biometrician dispute can, as stated previously, be best understood as a disagreement regarding the compositional nature of populational heredity. The biometricians viewed heredity as a blending fluid or force transmitted principally vertically from distant stem to current generation, distilling the ancestral influence of multiple generations down to the present and offering plentiful material for a directive and creative selection to operate with (Ibid.). By contrast, for the Mendelians heredity was highly granular in quality and principally transmitted within populations horizontally between parent and offspring generations. The granular and ahistorical nature of Mendelian heredity was disguised by a combination of environmentally generated phenotypic variability and the intergenerational recombination of hereditary factors. Mendelism did not therefore simply represent an unfortunate recrudescence of anti-Darwinian typological thinking a lá Mayr but rather constituted chiefly a set of alternative propositions as to the compositional nature of evolving populations. This is not to deny that a number of Mendelians would, in the development of their research programme, assume the tendency for a certain structure to hereditary transmission that at the individual and populational level would tend to express itself in a typical form - the 'wild type' - from which variation would be rare, especially in nature. But this is not in my view evidence of belief in an underlying 'species essence' but rather of a recognition of the holistic character of organisms and the interactive contribution of hereditary factors in their development. The contrast to this holism is not populationism but 
rather atomism. I will now examine the (unappreciated) holism of a key early Mendelian (and chief opponent of the biometricians), William Bateson, in particular emphasising the important relationship between his use of the wild type concept and his notion of the "normal body'. I will then show how this holism about wild types was challenged by the Morgan group's increasingly genocentric research into chromosomal linkage, which would eventually lead to the disintegration of the wild type concept.

\section{Bateson contra Weldon}

William Bateson (1861-1926) was an early adopter of Mendelism and was one of its most prominent advocates in the early decades of the twentieth century, being responsible for organising the first translation of Mendel's papers into English. It has even been argued that given his better appreciation of the importance of Mendel's paper compared to the traditional 'rediscoverers' (de Vries, Correns and Tschermak), Bateson should therefore be regarded as Mendel's chief 'rediscoverer' (Keynes and Cox, 2008). More importantly perhaps, however, was Bateson's defence of Mendelism against early attacks from the biometricians Weldon and Pearson. Bateson's disagreements with the two biometricians considerably predated the controversy over Mendelism. In the early 1880s, Weldon and Bateson had both trained together as morphologists in Francis Balfour's Cambridge laboratory before going their separate ways. Whereas Weldon attained secure teaching employment at the University and became part of the Darwinian orthodoxy, Bateson remained on the fringes and became attracted to the notion of evolution as driven by discontinuous variations caused by internal physiological changes (Olby, 1989). Prior to reading Mendel in 1900, Bateson had failed to find conclusive evidence as to the nature of these underlying causes despite conducting extensive experimental research both in the field in Central Asia and nearer to home in his Cambridge garden. Reading Mendel, Bateson discovered a ready-made methodology for investigating heredity and variation, one that moreover produced rapid results when put into practice. Better still, Mendel's law of segregation appeared to support Bateson's contention that variation was non-blending and therefore discontinuous in nature (Müller Wille and Richmond, 2015; Darden, 1977).

The subsequent feud between Bateson and Weldon and Pearson was in many ways a product of a limited understanding of one another's ideas and a clash of egos. Provine notably argues that much of the dispute was due to a mutual assumption that Mendelism necessarily required endorsing discontinuous variation and was thus anti-Darwinian. Noting a 1904 Bateson remark that "when the unit of segregation is small, something mistakeably like continuous Evolution must surely exist", Provine remarks that "The history of population genetics might have been accelerated had Bateson, Pearson, and Weldon taken this remark to heart" (Provine, 1971, pp. 69-70). What is notable in retrospect, and of salience for the fate of the wild type concept, was the strength of Weldon's defence of Galton's theory of ancestral heredity. He concluded his 1902 paper, 'Mendel's laws of alternative inheritance in peas', with the following sharp rebuttal:

"The fundamental mistake which vitiates all work based upon Mendel's method is the neglect of ancestry, and the attempt to regard the whole effect upon offspring, produced by a particular parent, as due to the existence in the parent of particular structural characters; while the contradictory results obtained by those who have observed the offspring of parents apparently identical in certain characters show clearly enough that not only the parents themselves, but their race, that is their 
ancestry, must be taken into account before the result of pairing them can be predicted".

Weldon's key argument against Mendelism was therefore that its claim to have done away with the need for pedigree was false, as demonstrated by the existence of reversionary individuals that Weldon felt could only be explained as due to atavism caused by ancestral heredity. So long as a belief in the vertical transmission of deep ancestral hereditary influences was maintained, the purity of 'pure line' strains of sexually reproducing organisms would always remain in doubt, therefore rendering non-viable the notion of using standardised wild type lineages as controls for variation. Inversely, however, any attempt to disprove Mendelism through demonstrating non-Mendelian inheritance of atavistic characters could also be defended against if its 'wild type' lineages could be shown to be insufficiently pure. This is precisely what occurred in the Bateson-Weldon debate. Against Mendelism, Weldon appealed to work done on inheritance in mice by the German biologist Johann von Fischer, which appeared to demonstrate non-Mendelian atavism. Bateson, on investigating von Fischer's work, advised that it was unreliable due to the failure to distinguish between 'pure' homozygous and 'hybrid' heterozygous wild type mice (the unaccounted for recessive traits of the latter being the source the 'atavism' in the experiment) (Provine, p. 73). The Mendelian-biometrician debate thus established early on the importance of properly standardised and homozygous wild type strains as central to the strategy of classical genetics.

\section{Bateson on the 'Presence and Absence' System, Wild Type and the 'Normal Body'}

Having examined the importance of wild type in Bateson's initial defence of Mendelism, I will now establish the centrality of the wild type concept in Bateson's overall genetic thinking by looking at a particular aspect of his thought that I believe is otherwise difficult to understand, namely his version of the 'presence and absence' model of dominance. This model suggested that in cases of complete dominance the recessive trait could be treated as 'absent', not inactivated. This was suggested by Correns and Cuénot in 1903 as a theory of trait development, i.e. trait absence implied the absence of trait-producing factor product. But in 1906 C.C. Hurst went further by suggesting actual factor absence could be assumed in some cases. He thought this "appeal[ed] to the practical mind" more than the competing ideas of inactivated factors or factors for active absence. Bateson's adoption of the 'presence and absence' system later that year has been interpreted as due to Hurst's influence (Carlson, 1966). It has been suggested that one motivation may have been Bateson's desire to support the claim, against de Vries' assertion that they were evolutionarily unimportant 'retrogressive' mutations, that Mendelian strains were "nascent species", namely by arguing that if factor loss was irreversible then recessive mutation was a permanent move towards speciation, contra de Vries' belief that it was caused by reversible factor inactivation (Darden, 1977). Whether Bateson actually believed absent traits to imply absent factors is less clear. Raphael Falk (2001) has argued against this, maintaining that Bateson generally assumed factor product absences not actual factor absence. I find corroboration for this claim as, contrary to the common belief that Bateson failed to distinguish factors from factor products, he does exactly this in 1909 when he asserts that where an enzyme has been shown to be responsible for a heritable trait's production, it is "scarcely necessary to emphasise the fact that the ferment itself must not be declared to be the factor or thing transmitted, but rather, the power to produce that ferment, or ferment-like body". Returning to Falk, he maintains that Bateson actually conceived of dominance and recessiveness as "quantitative alternatives of the same unit-character" (2001, p. 286). On this view, a recessive mutation 
was a 'loss' in the sense that it was a loss of a factor's capacity to produce its usual quantity of product. $^{2}$

Bateson was not naïve about the problems of assuming actual factor absence. In his 1906 response to Hurst's paper reading, he pointed immediately to the problem of explaining "those cases where the negative character apparently dominates", e.g. dominant whiteness in chickens, and maintained that "until the problem is settled we shall be in constant difficulties" (Wilks [Ed.], 1907, p. 129). Along with 'negative' dominants, Bateson was also aware of 'additive' mutations such as human polydactyly that were dominant over the wild type or normal trait. The existence of both classes of mutation caused Bateson to reject de Vries' early idea that dominance correlated with phylogenetic age. This assumption worked well for the majority of mutations, which were recessive, but not for dominant mutations, especially those not known in nature. Bateson therefore denied that dominance and ancestral age were correlated with each other or with the wild type. What I believe Bateson instead associated the wild type with was the 'normal body' (see Bateson, 1909, p. 232) by which I speculate him to mean the organism as produced by the 'normal development' of the species as determined by phylogenetic history (i.e. the view of development Bateson was inculcated in as a Cambridge morphologist). Whether a trait was considered normal or variant was relative to a species' evolutionary and developmental history, for this is what determined its wild type in nature. The wild type as 'normal body' thus became for Bateson a necessary reference determining what constituted variation and whether it was additive or deleterious.

The normal body is also the body of the healthy organism, and it was from the study of hereditary diseases that Bateson drew many of his metaphors for variation. In 1894's Materials for the Study of Variation, he endorsed Virchow's view that "every deviation from the type of the parent animal must have its foundation on a pathological accident" (p. 74). From 1902 onward he became an early champion of Archibald Garrod's research into 'inborn errors of metabolism' (Harper 2005). Garrod had shown that congenital disease could be caused by genetic deficiency, "the absence of some ingredient which is present in the normal body". This became Bateson's model for general recessive variation. But Bateson also believed disease could occur through the unwanted presence of an alien influence, asserting that "If... a disease descends through the affected persons, as a dominant, we may feel every confidence that the condition is caused by the operation of a factor or element added to the usual ingredients of the body. In such cases there is something present, probably a definite chemical substance, which has the power of producing the affection" (Bateson, 1909, p. 232). The analogy between invasive disease and dominant mutation is especially evident in this 1913 remark: "Just as when typhoid fever breaks out in his district the medical officer of health knows for certain that the bacillus of typhoid fever has by some means been brought into that district so do we know that when first dominant white fowls arose in the evolution of the domestic breeds, by some means the factor for dominant whiteness got into a bird, or into at least one of its germ-cells" (pp. 93-4). The dominant mutant factor was thus conceived as an invasive pathogen that disrupted the normal body and entered the germ-line, so becoming heritable. Such traits were rare in nature because they were usually maladaptive and

2 I think Falk's argument persuasively illustrates one way Bateson interpreted 'presence and absence'. However, I think Bateson's degenerationist theory of 1914, detailed below, certainly assumes actual factor loss, and therefore it may be the case that Bateson drifted between 'absence' as factor product absence and 'absence' as actual factor absence. 
destroyed by natural selection. Under domestication, the more wayward hand of artificial selection allowed the perpetuation of such forms.

Alongside this pathogenic explanation of dominant mutation, Bateson also speculated whether a unified mechanism could instead account for both deleterious and additive variation. In 1904, Bateson had mused that 'negative' dominant mutants might be caused by "the presence of some inhibiting influence" in the germline (Cock and Forsdyke, 2008, p. 251). When such inhibitors were removed, these formerly repressed factors would express themselves as dominant mutations. In 1909, Bateson noted that "When from a single wild type, man succeeds in producing a multitude of new varieties", this uncovering of recessive variation could be regarded as "a process of "unpacking"'” (p. 280). In 1914, Bateson extended this hypothesis, positing that "the [entire] course of evolution can... be represented as an unpacking of an original complex which contained within itself the whole range of diversity which living things present" (pp. 298-9). Bateson proposed that some novel traits could be caused by the fractionation of factors (e.g. pied mammalian coat colouration) and others by the complete loss of inhibiting 'epistatic' factors. For instance, Bateson suggested the production of domestic varieties of the apple was the result of the progressive loss of epistatic factors originally present in the wild type crab apple. In other words, the wild type possessed potentially all the variation found in domestic varieties but needed to be 'unpacked' in order for this to be expressed. This degenerationist theory of evolution could account for both recessive and dominant mutations without positing the generation of new factors, and because such changes were claimed to be irreversible acted to justify Bateson's claim that Mendel's strains were incipient species. I will not dwell on the many flaws of Bateson's hypothesis. I will instead note that as well as legitimating the status of Mendel's strains as models of evolutionary variation, this theory both assigned the wild type a place as a real unit of nature and valorised the geneticist's efforts to understand species by 'unpacking' them. Bateson's was thus a holistic interpretation of wild type which reinterpreted laboratory decomposition as not an end in itself but rather a means towards understanding the whole through particular analysis.

Bateson had further theoretical reasons for his holistic treatment of wild type. He believed factors would require a pre-existing milieu within which to interact, a biological equivalent of the electromagnetic fields of physics (Rushton, 2014). He called this milieu, thought more fundamental than any trait or factor, the 'residue'. The idea first appears in a 1902 collaboration with Edith Saunders. The question is raised of whether "we rightly conceive of the whole organism as composed of such unit-characters" (as was argued by the atomist de Vries), "or is there some residue - a basis - upon which the unit-characters are imposed?" (p. 148). Bateson and Saunders, favouring the latter, hypothesised that the residue might be responsible for interspecies reproductive incompatibility. They believed hybrid sterility could not simply be due to parental factor differences as Mendelian varieties could still cross without issue, so speculated that differences in the organisational substratum scaffolding factors might disrupt the integration of parental inheritances in species hybrids. Organisms of dual heritage would be unable to form sex cells due to being mosaic individuals, and this accounted for hybrid sterility. This theory of residue-based speciation was most likely inspired by George Romanes' earlier hypothesis of physiological selection, which posited that new species might form through the spontaneous appearance of mutual infertility within a population (Forsdyke, 2009). By maintaining that it was constitutional organisation, not variational difference, which demarcated species, Bateson and Saunders allowed for 
considerable germinal variation within a species (including Mendelian 'nascent species'). This contradicted the de Vriesian paradigm whereby speciation was conceived purely in terms of variation in factor number or activity. As to what this residue consisted of, Bateson was not clear, save that it was an "irresoluble base" which remained unchanged throughout a species' history (Bateson, 1902, p. 26). It was likely this substratum that Bateson had in mind when he later spoke of wild types being 'unpacked' during genetic analysis. The residue acted as a container for species-particular factors. In the wild type, all 'slots' were full, in recessive mutants, some empty or inactive. Genetic analysis, by studying recessives, 'unpacked' the wild type and in doing so offered hints as to its underlying organisational structure, which if determined would allow geneticists to establish the true nature of species differences. The wild type thus retained primacy over mutants and individual factors, for whilst factors were the units of analysis, they were mere means to understanding the larger complex of the species, of which the wild type was the normal, undecomposed instance.

\section{The Morgan Group}

The virtues of the 'presence and absence' system were threefold: its explanation of dominance as the imposition of presence over absence was easily understood; it did not invoke a virtus dormitiva as did property-based theories of dominance; and it retained a developmental and interactive role for factors, which was looked upon favourably by embryologists, most of whom favoured regulative models of development which presupposed that the cellular context, and not a pre-programmed parcelling out of determinants (as assumed by Weismann and de Vries) was responsible for determining specialisation. Despite these advantages, the functionalist 'presence and absence' research programme would after 1912 be rapidly eclipsed by the Morgan group's structuralist research programme studying chromosomal genetic linkage. ${ }^{3}$ Much has been made of 'presence and absence' models' apparent inability to account for multiple allelism and back mutations (see, for example, Darden, 1991). I believe Falk has shown that Bateson's model was more than malleable enough to account for these difficulties. Other factors must therefore be sought out to account for the Batesonian programme's decline. I believe it was principally held back by its lack of a detailed account of heredity's structure and materiality. These deficits can partly be attributed to Bateson's commitment to a dynamic developmentalist interpretation of factors and his consequent scepticism of efforts to link factors with 'static' material carriers like chromosomes (Rushton, 2014). This is not to say that Bateson and his collaborators ignored the material nature of factors - in fact, they had early success in studying the chemical nature of trait production, e.g. Muriel Wheldale's research into the role of enzymes in colour production in snapdragons (Olby, 1994, p. 133-5). But this research only uncovered the biochemical role of factor products, not factors themselves.

The inability of Batesonians to directly access factors left them dependent on making inferences from visible traits. The presence and absence system was especially contingent on such inferences and was criticised on these grounds by the Morgan group in 1915.

\footnotetext{
Whilst studying different aspect of genetic phenomena and therefore not inherently incompatible, the two approaches, in focusing on different research questions and strategies, competed for resources and personnel. With the Batesonian research programme being increasingly perceived as stagnating after early successes (as well as carrying the additional ballast of Bateson's increasingly unfashionable agnosticism over hypothetical entity claims), the productivity of the Morgan group's breeder-reactor Drosophila research model won over more and more converts, resulting in strictly functionalist approaches to genetics dropping out of vogue and losing the power to draw in adequate researchers and funding.
} 
"[P]resence and absence", they contended "assumes that we do know something about the relation between character and factor that we can not possibly know. To assume the absence of a factor from the absence of a character is, in a sense, as naive as it was to assume that an animal moved toward light because it liked the light" (Morgan et al., 1922, p. 274). As we have seen, this criticism is somewhat unfair given that Bateson did assume that 'absent' dominants were due to present factors that interfered in the production of the wild type trait. But Bateson was only able to make this interference through his assumption of the wild type as 'normal body' and mutations as deleterious or invasive. This was not the only view of wild types prominent among early geneticists - some were committed Darwinians who treated wild type as a largely historical category, others were mutationists who like de Vries believed the difference between wild and non-wild types was a matter of viability in nature.

Thomas Hunt Morgan was an early mutation theory enthusiast but one with idiosyncratic views on variation and evolution. Like de Vries, Morgan dismissed both Darwin's claim that domestic varieties were 'incipient species' and Bateson's assertion that Mendel's strains were 'nascent species'. His chief cause for doing so was the continued interfertility of these varieties with their parent types. In a possible dig at Bateson, he comments that "discontinuity in itself, unless it involved infertility with the parent species... cannot be made the basis for a theory of evolution" (Morgan, 1903, p. 286). Bateson, as we know, was aware of the problem of the origins of interspecific sterility and believed its cause lay in the organisational scaffolding of heredity and that factor change alone was not sufficient. Morgan, by contrast, thought factor changes alone sufficient but was sceptical of the evolutionary importance of de Vriesian macromutation. Instead, he theorised that speciation occurred through the accumulation of micromutations, not through selection as Darwinians held but rather through directional variation (orthogenesis) during rare 'mutating periods'. Morgan's theory differentiated wild types and domestic varieties as only the former were thought produced by directional variation, as evidenced by their hybrid sterility. Domestic varieties remained interfertile and required maintenance through vigilant selection because they were developed piecemeal out of extant variation. Because of the 'unnatural' origin of domestic varieties, Morgan deliberately chose a 'wild' organism for his experimental evolution studies, the fruit fly Drosophila melanogaster (Kohler, 1994). 'Wildness' was therefore an important prior condition for his experiments.

Laboratory domesticated Drosophila are of course no longer wild. But Morgan believed that as long as his stocks were genetically indistinguishable from their wild ancestors, they still retained a 'wild' hereditary constitution and were therefore adequate substitutes for reallywild flies. This attitude surfaces in a 1910 paper where Morgan, describing crossing a mutant white-eyed female and a "wild, red-eyed male", adds the qualification that this cross is more accurately the pairing of a mutant and "an individual of unrelated stock", i.e. an individual 'wild type' for the mutant trait. The implication is that any individual bearing the wild type trait can be effectively treated as 'wild' for that trait so long as it produces the expected Mendelian offspring ratios in crosses. This was likely already Morgan's experimental practice in 1910, given he was well aware of the time-consuming nature of domestication and the risks of fresh wild stock introducing hidden genetic variables. It therefore made sense that he would favour a transition from using really-wild flies in experiments to using their labborn 'wild type' descendants. Morgan's student Calvin Bridges would later (1917, p. 457) make a similarly pragmatic clarification when he stated that "Flies which show no mutant 
characters are said to be wild-type (+)", i.e. any fly which lacks visible mutation is treated as 'normal'.

\section{Remodelling Wild Types \& Defending Against Critique}

The story of how Morgan in early 1910 discovered the sex-linked mutant white, thus becoming convinced of the 1902 Sutton-Boveri hypothesis that chromosomes were the material carriers of factors, has been told elsewhere (e.g. Kohler, 1994). Morgan, once an arch-critic of the chromosomal hypothesis, was far from the first geneticist convert, but was first to make the key insight that the rarity of 'complete coupling' - the complete coinheritance of same-chromosome traits - could be explained as due to homologous chromosomes exchanging segments when conjugating during meiosis (Carlson, 1966). This theoretical mechanism of 'crossing over' allowed Morgan to explain differential rates of coinheritance between factors as due to their relative distance between each other (their 'linkage') on a chromosome. By contrast, Bateson and his colleague Punnett spent seven years investigating various phenomena they termed 'partial coupling', 'repulsion' and 'partial repulsion', i.e. different manifestations of associative inheritance, but their continued chromosomal scepticism led them into the blind alley of increasingly elaborate hypotheses relying on "enormously complex series of cell divisions... proceeding with mathematical regularity and precision, but in a manner for which direct observation furnishes no basis" (Sturtevant, 1914, quoted in Carlson, 1966, p. 55). The Batesonian method of genetic analysis here displayed the weakness incurred by a lack of access to the materiality of factors and a consequent dependence on inference from deceptive external appearances. The Morgan group, by contrast, would develop a correlational method which by linking the distribution of phenotypic traits with the observed behaviour of chromosomes effected a form of "multiple determination" (Wimsatt, 2007).

Morgan's insights into genetic structure removed major obstacles to the chromosome theory and enabled the great modelling project of classical genetics, linkage mapping. This enterprise was principally led by three of his students - Sturtevant, Calvin Bridges and Hermann J. Muller. They would radically reconstruct their group's Drosophila strains for this project's purposes. Morgan had used pure line breeding as part of his experimental evolution studies but had otherwise retained much of his stocks' natural variability. However, accurately measuring distances between factors required healthy fly stocks with chromosomes that had relatively uniform rates of crossing-over. One of the main tasks of Morgan's students was therefore to 'debug' Drosophila by breeding out factors that suppressed or modified crossing over. But the eventual standardised Drosophila genome was not simply what was left over after 'debugging'. Rather, both mutant and 'wild type' strains were constructed to meet the laboratory's demands, e.g. being vigorous, fecund, able to thrive at room temperature on a standard diet, and free from 'bad habits' (under this title, Bridges and Morgan include proclivity to drowning, getting stuck in food, and reticence to leave the culture bottle) (Kohler, 1994). Whilst much of the emphasis in the literature has been placed on fitting mutants to laboratory circumstances, I wish to emphasise that the demands of experimentation equally applied to the selection of 'wild type' control stocks. The consequence of these modifications was that the standard Drosophila 'wild type' strains developed by the Morgan group were superbly well fitted to their role in the experimental assemblage of linkage mapping. But they were also exceptionally domesticated organisms lacking much of their species' natural variability, and their 'wildness' and 'typicality' was therefore open to dispute. 
We have seen that Morgan's instrumentalist attitude towards 'wild type' allowed lab-born individuals to be termed wild type for a characteristic if the trait was 'normal' in nature. Morgan's students Sturtevant, Bridges and Muller were not only similarly instrumentalist but also substantially more committed to mechanistic and reductionist approaches to the life sciences (Roll-Hansen, 1978). These commitments inclined them to treat Drosophila as an aggregate as opposed to interactive product of its factors. This assumption that wild types could be decomposed into wild type genes was moreover key to the claim that the mosaic of 'normal' traits and genes which constituted lab wild types could act as representative of the species in nature and that knowledge produced in the lab could therefore consequently be unproblematically extrapolated to the wild. The Morgan group knew such claims were counter-intuitive, so therefore made strident efforts to pre-empt critique. They made clear their awareness of the artificial uniformity of the laboratory milieu by highlighting examples of mutations not phenotypically expressed under ordinary lab conditions, e.g. 'abnormal abdomen', which only manifested in mutants fed on non-standard wet food. Such instances demonstrated that hidden variability could be masked by ordinary lab conditions. But the possibility of cryptic variation undermining the reliability of lab standards was dismissed. Geneticists might need to discover the "special environment" required to express hidden mutations, but generally the standard lab environment was treated as a "normal", neutral experimental background (Morgan et al., 1922, p. 38). The idea that cryptic mutations might compromise the homogeneity of wild type strains also appears implicitly dismissed, the assumption likely being that the dragnet of naked eye observation combined with Mendelian analysis would tend to eventually detect and resolve stock anomalies (this was, after all, 50 years before Kimura's theory of neutral mutations).

More troubling for Morgan was the sceptical questioning of whether experimental interventions in laboratory genetics had any true correlate in nature, as was required for their claim to stand in for natural evolutionary phenomena. "If we are ever able to discover what part hybridization plays in evolution", the mouse geneticist Maud Slye remarked in 1915 (pp. 246-7), "it is immeasurably more valuable to find out the behaviour of natural species rather than of forms created in the laboratory under more or less artificial conditions, and which are never found outside the laboratory". Specifically, she thought it "still open to question whether the wild house mouse (Mus musculus) inevitably furnishes actual 'homozygotes' which will stand every test of the theoretical 'homozygote", i.e. whether actual wild types ever approach the artificial uniformity of 'wild type' lab strains. To avert this issue, Slye insisted on corroborating results attained using "artificial laboratory" strains by repeating crosses using "wild housemice". Slye's target was fellow mouse geneticist C.C. Little, but such anti-reductionist scepticism could equally be applied to the Morganian research programme. Morgan anticipated such criticism, asserting that to question the extrapolation of his group's results to "evolution in the 'open', nature 'at large' or to 'wild' types" due to the lab's "artificial and unnatural conditions" would also necessitate questioning "the use of the spectroscope in the study of the evolution of the stars... the test tube and the balance by the chemist, [and] the galvanometer by the physicist". He declared all these "unnatural instruments used to torture Nature's secrets from her". Nature, Morgan maintained, must be treated unnaturally to be studied exactly, the "real antithesis" being "not between unnatural and natural treatment of Nature, but rather between controlled or verifiable data on the one hand, and unrestrained generalization on the other" (Morgan, 1916, pp. 84-5). Lab wild types were therefore necessarily artefactual tools for the production of exact and useful scientific 
knowledge. Their differences with real wild types were epistemically inconsequential, as without artificial standardisation genetics could not be an exact science.

\section{Completing the Decomposition of the Wild Type}

The move to linkage mapping heralded a shift in genetics away from typological holism and towards instrumental interpretations of 'wild type' as relative to the particular trait or gene under study. This move towards relative or token wildness was accompanied by an increasing tendency to decompose wild types into 'wild type' genes and to ignore the role of gene-gene and gene-environment interactions in trait development. The transition from dynamic interactionism to a more static genocentrism had definite epistemic advantages but also triggered the closure of previously important avenues of investigation. 'Presence and absence' models of genetics had been phenomenalist and uninformative regarding genetic structure. But the linkage studies that displaced them had next to nothing to say about gene function. Morgan recognised the deficiencies in these individual research strategies and therefore insisted on their necessary complementarity. Transmission and development should be studied in independent synchrony, with the aim of eventual reintegration when the fields matured. But the actual outcome of evicting ontogenetic concerns from transmission genetics was a narrowed perspective and decreased dialogue with developmental biology (Amundson, 2005).

Morgan's own engagement with developmental genetics after 1910 faltered despite initial enthusiasm. ${ }^{4}$ In 1912, he attempted to develop a more sophisticated version of 'presence and absence' in order to account for the role of factor interactions in the wild type and mutant trait production. He illustrated the new nomenclature using the example of the rudimentaryminiature wing mutation complex. Wild type, where both dominant $\mathrm{R}$ and $\mathrm{M}$ were present, was RM; the recessives rudimentary and miniature were $\mathrm{Rm}$ and $\mathrm{rM}$ respectively, and the double recessive rudimentary-miniature was $\mathrm{rm}$. Notably, Morgan also assigned a role for the 'residuum', echoing Bateson's residue but, instead of treating it as an underlying organisational structure, reinterpreted it as constituting the totality of the organism's remaining genes and their products. The 1912 nomenclature emphasised the dependence of individual factors on this genomic background - whilst $\mathrm{R}$ and $\mathrm{M}$ were important for normal wing development, their absence did not imply the absence of wings. "[S]uch an interpretation", Morgan explained, "rest[s] on a false conception... of Mendelian factors; for, the absence of $\mathrm{R}$ and of $\mathrm{M}$ does not mean that all factors for wing are lost - there may be hundreds of factors that enter into the production of wings - but only that when a certain factor, $\mathrm{R}$, is lost from the complex, a miniature wing is produced by the remainder; and when the factor $\mathrm{M}$ is lost from the complex of wing-factors, a rudimentary wing is produced by the remainder. When both $\mathrm{R}$ and $\mathrm{M}$ are absent the remaining factors are still capable of forming as much of the wing as is shown by the rudimentary-miniature wing". Individual genes thus did not make a difference in isolation, being only difference-making in the context of the whole genome. Genes contributed to trait development but there were, as Falk surmises "no genes for traits" (Falk, 2009, pp. 231-3). Consequently, whilst one could analyse an organism

4 Morgan did later in 1934 return to the topic of the relationship between heredity and development in his 1934 book Embryology and Genetics but his attempt to bring the two fields closer again is judged by Allen (1985, pp. 110) "remarkably unsuccessful". An oft-repeated anecdote regarding the book is that a disappointed colleague, expecting a work that would offer a new synthesis of the two fields, was halfjokingly told by Morgan: "Well, what did you expect? I did exactly what I said I would do in the title: I discussed embryology and I discussed genetics"! 
into its mere composite of traits and genes, it was in truth a whole the nature of which only emerged in interaction. The wild type too remained such a whole.

Just 3 years later, the Morgan group quietly dismissed the 1912 system, now nonchalantly stating, for instance, that for the pink eye colour mutation "we may say that a particular factor (p) is the cause of pink". They claimed this was not a move to crediting single factors with producing whole traits. By 'cause', they simply meant "that a particular system differs from another system only in one special factor" (Morgan et al, 1922, p. 263). This move from a holistic account of causality to a difference-making one established the 'differential concept of the gene' prominent in genetics ever since (Schwartz, 2000). Motives for abandoning the 1912 nomenclature included the fact that it was "not sufficiently elastic", becoming cumbersome if three or more interacting factors were added, and was further impractical as its terms required changing with each new mutation added (Morgan, 1913, p. 12).

Furthermore, the number of mutations the Morgan group was finding greatly outstripped the nomenclature's capabilities - for just eye colour, 25 mutations were known by 1915 (Kohler, 1994, p. 61). The switch to a differential account of mutation is thus easily understood. This does not escape the genocentric nature of the new nomenclature. To produce the insensitive background against which difference-making gene action was measured, all other factors were held as ceteris paribus conditions. Whilst the Morgan group knew the residuum to be causally active in all trait development, its treatment as a static backdrop transferred much of its perceived causal agency to the gene. In contrast to the 1912 model's minimisation of individual factor contributions to development, the new system leant genes illusory autonomy as 'atoms' of heredity and uncontextualised power as difference makers. ${ }^{5}$ The widespread adoption of the differential concept of the gene thus contributed to the decomposition of the wild type into its component wild type genes, thus legitimating the strategy of treating individuals as standing in for the wild type so long as they possessed genes deemed wild type. This compositional notion of the wild type would then dominate classical genetics.

\section{Conclusion}

To summarise, how were lab wild types thought to represent nature's wild types? I earlier emphasised that there has been a long history of scientists using domestic organisms as standins for wild ones. Darwin maintained, against orthodoxy, that wild and domestic varieties were produced through similar processes. His analogies were challenged by, among others, Weismann and Galton, but by promoting the sanctuarisation and devitalization of heredity, these theorists simultaneously encouraged the idea that if the nature of wild type could be

\footnotetext{
5 This atomisation of the gene of course paved the way for the idealised portrayal of genes as free-floating ideal molecules of heredity (much like Boyle's ideal gas molecules) in the work of early population geneticists such as Fisher, Haldane and Wright, works regarded, moreover, as foundational to the Modern Synthesis. This is another reason I dislike Mayr's typological/populational distinction as applied to issues regarding heredity as opposed to selection, namely that it encourages the genocentric tendency to ignore the fact that the component genes of an individual's genome are by and large far more integrated than the component individual organisms of a natural population. Because of this greater level of integration, questions of structure are of paramount importance, with atomism vs. holism/interactionism being the key point of contention. It is not clear which side of the typological/populational divide atomism or holism should fall, especially given one can be an atomist about individual constitution and assume little populational variation (like de Vries), or be a holist about individual constitution but assume large populational variation by positing high levels of inbuilt genomic-developmental robustness/redundancy. One thing a genome or population of genomes most certainly does not resemble is a cloud of free-floating and autonomous gene molecules.
} 
attached to the hereditary constitution, then it could be transferred for study under controlled conditions without being distorted by the move from nature to an artificial environment. However, once wild type become associated with hereditary constitution, it was vulnerable to disintegration if the genotype proved atomisable, as de Vries believed it to be. Bateson, by tying the wild type to the development of the normal body, allowed wild type to survive as a holistic concept irreducible to individual factors and traits. This interactionist account of wild type was ultimately rejected by the Morgan school due to its dependence on inferences from external appearances, a weakness exposed by Bateson and Punnett's reliance on highly speculative models to explain partial coinheritance. By adopting the chromosomal theory and deducing the hypothetical mechanism of crossing-over, the Morgan group were able to corroborate their theoretical claims with cytological observations of chromosomal behaviour. They furthermore developed linkage maps that gave previously putative factors a concrete positional space. But the discovery that chromosomes were fractionable and recombinable augmented the inclination to atomise factors and to decompose wild types into wild type genes. This was reinforced by the Morgan group's decision to adopt a differential account of gene action after abandoning interactionist nomenclature. This linguistic shift epistemically privileged genes over genome and individual gene action over interaction. Atomisation of the wild type was further advantageous as by treating the gene not the type as the 'wild type' element, geneticists could justify treating any lab strain as 'wild type' so long as the strain had the wild type characteristics relevant for a particular experiment.

Atomisation of course ignored epistatic gene interactions and the need to breed out interfering factors for maximal decomposability. When in the 1940s and '50s Theodosius Dobzhansky would criticise the Morgan group's use of inbred lab strains as 'wild types', he would highlight the fact that among the interfering factors bred out in the mid-1910s were inverted chromosomes. Dobzhansky found these to be common in wild Drosophila populations and theorised that their suppression of recombination might prevent adaptive gene combinations breaking up (Falk 2009). He identified a further troubling problem with using lab wild types as representatives for nature, namely the high level of natural variation suggested by cytological observation of chromosome banding. Dobzhansky subsequently declared the wild type concept 'refuted', asserting that it was representative of a form of "typological thinking, the roots of which go down to the Platonic philosophy, [and] is basically anti-evolutionistic" (Cordeiro and Dobzhansky, 1954, p. 83). But despite his claims that the wild type concept could only exist "because of the reluctance of the human mind to abandon the idea of a finite number of static prototypes underlying the unmanageable... multiformity of the living nature", he nevertheless admitted that "it is... [in non-polymorphic species] convenient for descriptive purposes to contrast mutant or aberrant individuals or strains with normal or wild type ones" (Dobzhansky et al., 1945, p. 287).

It is perhaps to this pragmatic use of wild type that we can return. Lab strains can never represent their species holistically (nor can any single wild individual lineage), but they do so partially, and in the case of highly conserved genetic complexes (e.g. those important for viability) variation is usually insignificant across the domestic-wild divide. Indeed, many such complexes are evolutionarily so heavily conserved that they allow model organism lab lineages to be used to stand in for species vastly separated from them in phylogenetic time, including human beings. As long as this strategy's limitations are acknowledged, where analogies and homologies hold strong inferences can still be made, e.g. where an evolutionarily co-inherited gene with similar broad functions is studied in Drosophila or 
another model organism, it is reasonable to expect that some experimental findings can be extrapolated to humans and other species sharing these homologies. Furthermore, in the establishment of any experimental system, some form of norm is required to act as a control for variation, as without such a norm there is no standpoint from which to measure both the expected and unexpected effects of an intervention and no standardised background against which to detect interference from external factors. Wild types in classical genetics, as standardised strains utilised to study widely evolutionarily conserved aspects of heredity and variation, were generally able to adequately perform the role of standing in for nature in the laboratory, allowing the production of precise scientific data broadly extrapolatable to the wild, so long as their limitations as exemplars were acknowledged and accounted for. The shortcomings of wild type experimental systems correctly identified by their critics reflect these limitations, but the limitations of an experimental system are not indicative of failure. Thus whilst the experimental strategy of using wild type strains may have been based on false presumptions about the extent of natural variation, which cannot adequately be represented using genetically impoverished lab lineages, it has nonetheless proven a highly epistemically productive means of investigating the general mechanisms of heredity and causes of variation. 


\section{References}

Allen, G. (1978). Life Science in the Twentieth Century. Cambridge University Press.

Allen, G. (1985). Heredity under an Embryological Paradigm: The Case of Genetics and Embryology. Biological Bulletin, 168, Supplement: The Naples Zoological Station and the Marine Biological Laboratory: One Hundred Years of Biology, pp. 107-121.

Amundson, R. (2005). The Changing Role of the Embryo in Evolutionary Thought: Roots of EvoDevo. Cambridge University Press.

Ankeny, R. (2007). Wormy Logic: Model Organisms as Case-based Reasoning, In A.N.H. Creager, E. Lunbeck \& M.N. Wise (Eds.), Science without Laws: Model Systems, Cases, Exemplary Narratives, Duke University Press Books, pp. 46-58.

Ankeny, R. \& Leonelli, S. (2011). What's So Special about Model Organisms? Studies in History and Philosophy of Science, 42, pp. 313-323.

Anonymous. (1833). On Dwarfs and Giants. The Edinburgh New Philosophical Journal, 15, pp. 142151.

Bateson, W. (1894). Materials for the Study of Variation treated with Especial Regard for to Discontinuity in the Origin of Species. Macmillan and Co.

Bateson, W. (1902). Mendel's Principles of Heredity. $1^{\text {st }}$ Ed. Cambridge University Press.

Bateson, W. (1908). The Methods and Scope of Genetics. Cambridge University Press.

Bateson, W. (1909). Mendel's Principles of Heredity. $2^{\text {nd }}$ Ed. Cambridge University Press.

Bateson, W. (1913). Problems of Genetics. Yale University Press.

Bateson, W. (1914). Address of the President of the British Association for the Advancement of Science. Science, 60 (1026), pp. 287-302.

Bateson, W. \& Punnett, R.C. (1913). On Gametic Series involving the Duplication of Certain Terms. The Journal of Genetics, 1, pp. 292-303.

Bateson, W. \& Saunders, E.R. (1902). The facts of heredity in the light of Mendel's discovery. Reports to the Evolution Committee of the Royal Society, Vol. I., pp. 125-160.

Bell, T. (1837). A History of British Quadrupeds, including the Cetacea. London: John van Voorst.

Blyth, E. (1835). An Attempt to Classify the "Varieties" of Animals, with Observations on the Marked Seasonal and Other Changes Which Naturally Take Place in Various British Species, and Which Do Not Constitute Varieties. Magazine of Natural History, 8, pp. 40-53.

Bonneuil, C. (2008). Producing Identity, Industrializing Purity: Elements for a Cultural History of Genetics. A Cultural History of Heredity IV: Heredity in the Century of the Gene, Max Planck Preprint 343, pp. 81-110.

Bridges, C.B. (1917). Deficiency. Genetics, 2, pp. 445-465.

Carlson, E.A. (1966). The Gene: A Critical History. W.B. Saunders Company.

Castle, W.E. (1903). Mendel's Law of Heredity. Science, 18 (456), pp. 396-406.

Cock, A.G., \& Forsdyke, D.R. (2008). Treasure Your Exceptions, Springer Science.

Cordeiro, A. R. \& Dobzhansky, T. (1954). Combining Ability of Certain Chromosomes in Drosophila Willistoni and Invalidation of the "Wild-Type" Concept. The American Naturalist, 88, pp. 75-86.

Cornell, J.F. (1984). Analogy and Technology in Darwin's Vision of Nature. Journal of the History of Biology. 17, pp. 303-344.

Crawfurd, J. (1869). On the Theory of the Origin of Species by Natural Selection in the Struggle for Life. Transactions of the Ethnological Society of London, 7, pp. 27-38.

Darden, L. (1977). William Bateson and the Promise of Mendelism. Journal of the History of Biology, 10, 1977, pp. 87-106. 
Darden, L. (1991). Theory Change in Science: Strategies from Mendelian Genetics. Oxford University Press.

Darwin, C. (1888). The Variation of Animals and Plants under Domestication: Vol. 1 (2 ${ }^{\text {nd }}$ Ed.). London: John Murray.

Darwin, C. (1909). Essay of 1844. In F. Darwin (Ed.) The Foundations of the Origin of Species. London: Cambridge University Press.

Darwin, C. (2009). On the Origin of Species by Means of Natural Selection, or the Preservation of Favoured Races in the Struggle for Life, Penguin Classics. (Originally published 1859).

De Candolle, A.P. (1823). Memoir on the different Species, Races, and Varieties of the Genus Brassica (Cabbage), and of the Genera allied to it, which are cultivated in Europe. The Philosophical Magazine and Journal, 61, pp. 181-197.

De Vries, H. (1910). Intracellular Pangenesis. C. Stuart Gager (Trans.). Chicago: The Open Court Publishing Company.

De Vries, H. (1909). The Mutation Theory: Experiments and Observations on the Origin of Species in the Vegetable Kingdom, Vol. I: The Origin of Species by Mutation. J.B. Farmer \& A.D. Darbishire (Trans.). Chicago: The Open Court Publishing Company.

Di Teresi, C. (2010). Taming Variation: Typological Thinking and Scientific Practice in Developmental Biology. Thesis (PhD). The University of Chicago.

Dobzhansky, T. (1946). Genetics of natural populations. XIII. Recombination and variability in populations of Drosophila pseudoobscura, Genetics, 31, pp. 269-290.

Falk, R. (2001). The rise and fall of dominance. Biology and Philosophy, 16, pp. 285-323.

Falk, R. (2009). Genetic Analysis: A History of Genetic Thinking. Cambridge University Press.

Farber, P. (1978). A Historical Perspective on the Impact of the Type Concept on Insect Systematics. Annual Review of Entomology, 23, pp. 91-99.

Forsdyke, D.R. (2009). George Romanes, William Bateson, and Darwin's 'weak point'. Notes and Records: The Royal Society Journal for the History of Science. http://rsnr.royalsocietypublishing.org/content/64/2/139.

Galton, F. (1894). Natural Inheritance. New York \& London: Macmillan and Co.

Gayon, J. (1998). Darwinism's Struggle for Survival: Heredity and the Hypothesis of Natural Selection. M. Cobb (Trans.). Cambridge University Press.

Gliboff, S. (2001). The Pebble and the Planet. Thesis (PhD). Johns Hopkins University.

Gould, S.J. (2002). The Structure of Evolutionary Theory, The Belknap Press of Harvard University Press.

Griffiths, A.J.F., Gelbart, W.M., Miller, J.H. \& Lewontin, R.C. (1999). Modern Genetic Analysis. W.H. Freeman and Company.

Guttman, B., Griffiths, A., Suzuki, D. \& Cullis, T. (2011). Genetics: the Code of Life. New York: The Rosen Publishing Group, Inc.

Harper, P.S. (2005). William Bateson, Human Genetics and Medicine. Human Genetics, 118, pp. 141-151.

Hurst, C.C. (1907). Mendelian Characters in Plants and Animals. In Rev. W. Wilks (Ed.), Report of the Third International Conference 1906 on Genetics. London: Spottiswoode \& Co. Ltd.

Keynes, M., \& Cox, T.M. (2008). William Bateson, the rediscoverer of Mendel. Journal of the Royal Society of Medicine, 101, p. 104.

Knight, T.A. (1801). A Treatise on the Culture of the Apple and the Pear, and on the Manufacture of Cider \& Perry ( $2^{\text {nd }}$ Ed.). Ludlow: H. Proctor.

Kohler, R.E. (1994). Lords of the Fly: Drosophila Genetics and the Experimental Life, The University of Chicago Press. 
Jenkin, F. (1867). (Review of) 'The origin of species'. The North British Review, 46, pp. 277-318. (Originally published anonymously).

Little, C.C. (1921). Report of the Committee on Genetic form and Nomenclature. The American Naturalist, 55, pp. 175-178.

Mayr, E. (1959). Darwin and the evolutionary theory in biology. In: Evolution and Anthropology: A Centennial Appraisal. B.J. Meggers (Ed.), pp. 1-10. Washington, DC: Anthropological Society of Washington.

Mayr, E. (1973). The Recent Historiography of Genetics. In Evolution and the Diversity of Life: Selected Essays. [1976, pp. 329-353]. Cambridge, Mass. \& London: The Belknap Press of Harvard University Press.

Morgan, T.H. (1903). Evolution and Adaptation. The Macmillan Company.

Morgan, T.H. (1910). Sex Limited Inheritance in Drosophila. Science, 32, pp. 120-122.

Morgan, T.H. (1913). Factors and Unit Characters in Mendelian Inheritance. The American Naturalist, 47, pp. 5-16.

Morgan, T.H. (1916). A Critique of the Theory of Evolution. Princeton University Press.

Morgan, T.H., Sturtevant, A.H., Muller, H.J. \& Bridges, C.B. (1922). The Mechanism of Mendelian Inheritance (Revised Edition). New York: Henry Holt and Company.

Müller-Wille, S. (2011). Making Sense of Essentialism. Critical Quarterly, 53:4, pp. 61-77.

Müller-Wille, S. \& Rheinberger, H.-J. (2012). A Cultural History of Heredity. Chicago \& London: The University of Chicago Press.

Müller-Wille, S. \& Richmond, M.L. (2015). Revisiting the Origin of Genetics. In C. Brandt, H.-J. Rheinberger \& S. Müller-Wille (Eds.), Heredity Explored: Between Public Domain and Experimental Science, 1850-1930, Cambridge, MA: MIT Press.

Olby, R. (1989). The Dimensions of Scientific Controversy: The Biometric-Mendelian Debate. The British Journal for the History of Science, 22:3, Genetics, Eugenics and Evolution: A Special Issue in Commemoration of Bernard Norton (1945-1984), pp. 299-320.

Olby, R. (1994). The Path to the Double Helix: The Discovery of DNA. Dover Publications Inc. Ospovat, D. (1979). Darwin after Malthus. Journal of the History of Biology, 12, pp. 211-230.

Provine, W.B. (1971). The Origins of Theoretical Population Genetics. Chicago and London: The University of Chicago Press.

Roll-Hansen, N. (1978). Drosophila Genetics: A Reductionist Research Program. Journal of the History of Biology, 11, pp. 159-210.

Rushton, A.R. (2014). William Bateson and the chromosome theory of heredity: a reappraisal. The British Journal for the History of Science, 47, pp. 147-171.

Schwartz, J. (2008). In Pursuit of the Gene: From Darwin to DNA. Harvard University Press.

Schwartz, S. (2000). The Differential Concept of the Gene: Past and Present. In P.J. Beurton, R. Falk \& H.-J. Rheinberger (Eds.), The Concept of the Gene in Development and Evolution, Cambridge University Press, pp. 26-39.

Sebright, J. (1982). The art of improving the breeds of domestic animals. In a letter addressed to the Right Hon. Sir Joseph Banks, K.B. In C.J. Bajema (Ed.), Artificial Selection and the Development of Evolutionary Theory, Benchmark Papers in Systematic and Evolutionary Biology Vol. 4, Stroudsburg (Pennsylvania): Hutchinson Ross Publishing Company. (Originally published in 1809).

Shapin, S. (2010). Never Pure: Historical Studies of Science as if It Was Produced by People with Bodies, Situated in Time, Space, Culture, and Society, and Struggling for Credibility and Authority. John Hopkins University Press. 
Sloan, P.R. (1985). Ernst Mayr on the History of Biology (Review: The Growth of Biological Thought: Diversity, Evolution, and Inheritance by Ernst Mayr). Journal of the History of Biology, 18:1, pp. 145-153

Slye, M. (1915). A Reply to Dr Little. Science, 42(1077), pp. 246-248.

Sober, E. (1980). Evolution, population thinking, and essentialism. Philosophy of Science, 47, pp. 350-383.

Stanford, P.K. (2006). Exceeding our Grasp: Science, History, and the Problem of Unconceived Alternatives. Oxford University Press.

Sturtevant, A.H. (1914). The Reduplication Hypothesis as Applied to Drosophila. The American Naturalist, 48:573, pp. 535-549.

Weismann, A. (1891). Retrogressive Development in Nature. L.J. Gould (Trans.). In E.B. Poulton \& A.E. Shipley, Essays upon Heredity and Kindred Biological Problems, Vol. II, Oxford: Clarendon Press.

Weiss, K. (2013) Walk on the wild-type side. The Mermaid's Tale (Blog). http://ecodevoevo.blogspot.co.uk/2013/03/walk-on-wild-type-side.html. (Accessed 24/07/2014).

Wimsatt, W. (2007). Re-engineering Philosophy for Limited Beings: Piecewise Approximations to Reality. Harvard University Press.

Winsor, M.P. (2006). The Creation of the Essentialism Story: An Exercise in Metahistory. History and Philosophy of the Life Sciences, 28:2, pp. 149-174.

Winther, RG. (2001). August Weismann on Germ-Plasm Variation. Journal of the History of Biology, 4, pp. 517-555.

Witteveen, J. (2015a). "A temporary oversimplification": Mayr, Simpson, Dobzhansky, and the origins of the typology/population dichotomy (part 1 of 2). Studies in History and Philosophy of Biological and Biomedical Sciences, 54, pp. 20-33.

Witteveen, J. (2016). “A temporary oversimplification”: Mayr, Simpson, Dobzhansky, and the origins of the typology/population dichotomy (part 2 of 2). Studies in History and Philosophy of Biological and Biomedical Sciences, 57, pp. 96-105. 